\title{
Inferring the origin and genetic diversity of the introduced wild boar (Sus scrofa) populations in Argentina: an approach from mitochondrial markers
}

\author{
Mara I. Sagua ${ }^{1,2} \cdot$ C. E. Figueroa ${ }^{1,2} \cdot$ D. B. Acosta ${ }^{1,2} \cdot$ G. P. Fernández ${ }^{1}$ • B. N. Carpinetti ${ }^{3} \cdot$ D. Birochio $^{4} \cdot$ \\ Mariano L. Merino ${ }^{1,5}$
}

Received: 15 July 2017 / Accepted: 7 May 2018

(C) Mammal Research Institute, Polish Academy of Sciences, Białowieża, Poland 2018

\begin{abstract}
The Eurasian wild boar (Sus scrofa Linnaeus, 1758) was introduced into Argentina at the beginning of the twentieth century when individuals from Europe were taken to La Pampa province for hunting purposes. Starting from there, a dispersal process began due to the invasive characteristics of the species and to human-mediated translocations. The main objective of this study was to characterize for the first time, the phylogenetic relationships among wild boars from Argentina with those from Uruguay, Europe, Asia, and the Near East, along with diverse domestic pig breeds in order to corroborate the historical information about the origin of the local populations. To this end, we used mitochondrial Control Region and Cytochrome $b$ sequences from sampled Argentinian wild boars and retrieved from GenBank. The results showed that the majority of the Argentinian wild boar populations descend from European lineages, in particular of the E1 clade, according to the historical records. Remarkably, the population of El Palmar National Park had Asian origin that could be attributed to hybridization with local domestic pigs or to unrecorded translocations. Finally, genetic diversity in Argentinian populations was lower than in Europe and Uruguay meaning that wild boar in Argentina is still under the influence of founder effect and has experienced minor genetic introgression from domestic pigs, representing in this sense a reservoir of the original wild boar genetic variability.
\end{abstract}

Keywords Wild boar $\cdot$ Argentina $\cdot$ Control region $\cdot$ Cytochrome $b \cdot$ Phylogeny $\cdot$ Genetic diversity

\section{Introduction}

The Eurasian wild boar (Sus scrofa Linnaeus, 1758) occupies one of the widest geographic distributions of all terrestrial mammals, and this range has been greatly expanded by human

Communicated by: Karol Zub

Electronic supplementary material The online version of this article (https://doi.org/10.1007/s13364-018-0380-2) contains supplementary material, which is available to authorized users.

Mara I. Sagua

mara.sagua@nexo.unnoba.edu.ar

Mariano L. Merino

mariano.merino@nexo.unnoba.edu.ar

1 Centro de Bioinvestigaciones (CeBio), Universidad Nacional del Noroeste de la Provincia de Buenos Aires (UNNOBA-CICBA)/ Centro de Investigaciones y Transferencia del Noroeste de la Provincia de Buenos Aires CIT NOBA (UNNOBA-CONICET), Pergamino 2700, Buenos Aires, Argentina action. The species inhabits from Western Europe to the Russian Taiga, extending southward as far as North Africa, the Mediterranean basin, and the Middle East, through India and South East Asia to the islands of Sri Lanka, Taiwan, Japan, and the Greater Sunda Islands (Oliver and Brisbin
2 Consejo Nacional de Investigaciones Científicas y Técnicas (CONICET), Buenos Aires, Argentina

3 Gestión Ambiental/Ecología, Instituto de Ciencias Sociales y Administración, Universidad Nacional Arturo Jauretche, 1888 Florencio Varela, Buenos Aires, Argentina

4 Escuela de Producción, Tecnología y Ambiente, Universidad Nacional de Río Negro, Sede Atlántica, 8500 Viedma, Río Negro, Argentina

5 Comisión de Investigaciones Científicas de la Provincia de Buenos Aires (CICPBA), La Plata, Argentina 
1993). It is the ancestor of ancient and modern domestic pig breeds, and there is evidence to suggest that it was independently domesticated in several parts of its range, including Southeast Asia, the Far East, and Asia Minor (Oliver and Brisbin 1993; Larson et al. 2005). The Eurasian wild boar occupies a wide variety of temperate and tropical habitats, from semi-desert to tropical rainforests, temperate woodlands, grasslands, and reed jungles; often venturing onto agricultural land to forage. Since the early stages of expansion and dispersion of the Europeans, wild pigs and their domestic and feral derivatives have widely extended their distribution and established naturalized populations in Australasia, the Americas, and Oceania, in addition to a large number of oceanic islands (Crosby 1986; Oliver and Brisbin 1993; Oliver and Leus 2008). The success of this species as colonizer is based on its wide tolerance to different climatic conditions ranging from sub-Antarctic to tropical environments, its omnivorous diet, and the highest reproductive rate among ungulates (Read and Harvey 1989).

Wild boars were introduced into Argentina for hunting purposes in the early twentieth century. In 1909, Pedro Luro introduced seven wild boars (one male and six females) from France into a private game reserve currently known as Parque Luro Provincial Reserve (PLPR-La Pampa Province) (Amieva 1993). Later on, this first batch was reinforced with another one, whose origin is not clear. Several authors disagree when establishing an exact date of dispersal of these animals; Navas (1987) sets this event in 1914, while Amieva (1993) states it occurred in the 1930s, as a result of wire fence cutting during the construction of a national route. In the period between 1917 and 1922, a few animals from this original core were moved to Estancia Collun-Có (Neuquén Province), from where they began to disperse toward Nahuel Huapi (NHNP) and Lanín (LNP) National Parks, and Chile crossing the Andes (Daciuk 1978). Localities distribution is detailed in Fig. 1.

The second introductory event occurred in the 1910s when Aarón de Anchorena allegedly introduced wild boars from Spain to Isla Victoria (Neuquén Province) (Morales 1917; Biedma 2003). In 1928, this Argentinian landowner also imported boars of alleged Caucasus lineage into a property located in the southwestern Department of Colonia in

30

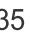

40

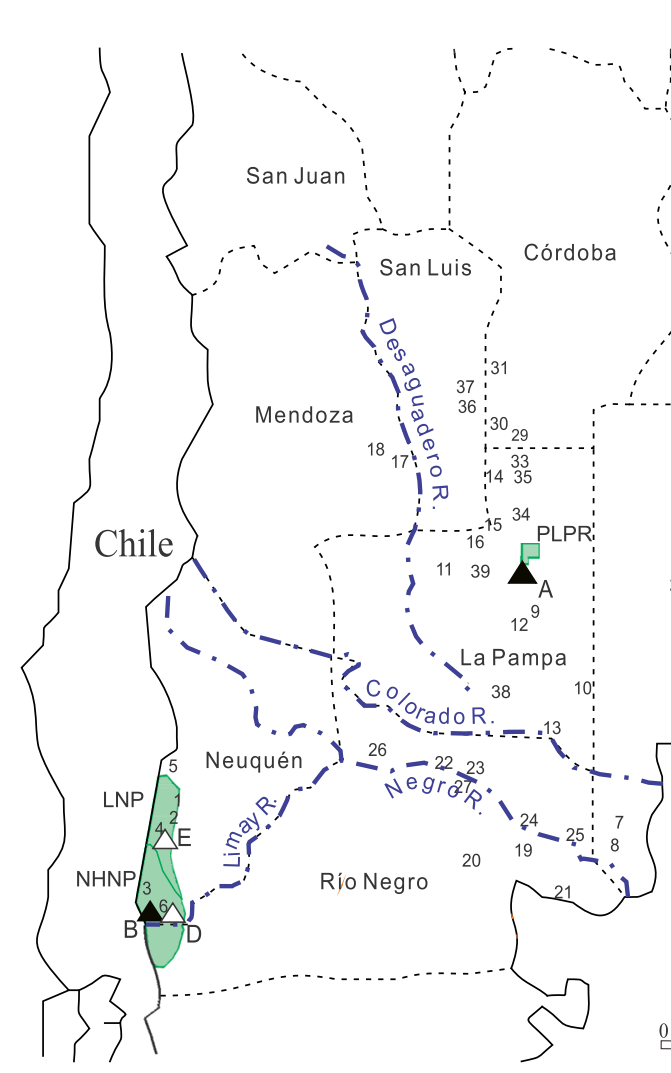

70
65

Fig. 1 Geographic distribution of the wild boar sampling sites in Argentina. Numbers correspond to the sampling sites detailed in Online Resource 2. Black triangles represent introduction sites at $\mathrm{A}=$ Parque Luro Provincial Reserve (La Pampa Province); B = Isla Victoria (Neuquén Province); C = El Palmar National Park (Entre Ríos Province). White triangles represent $\mathrm{D}=$ Huemul Ranch (Neuquén Province); $\mathrm{E}=$

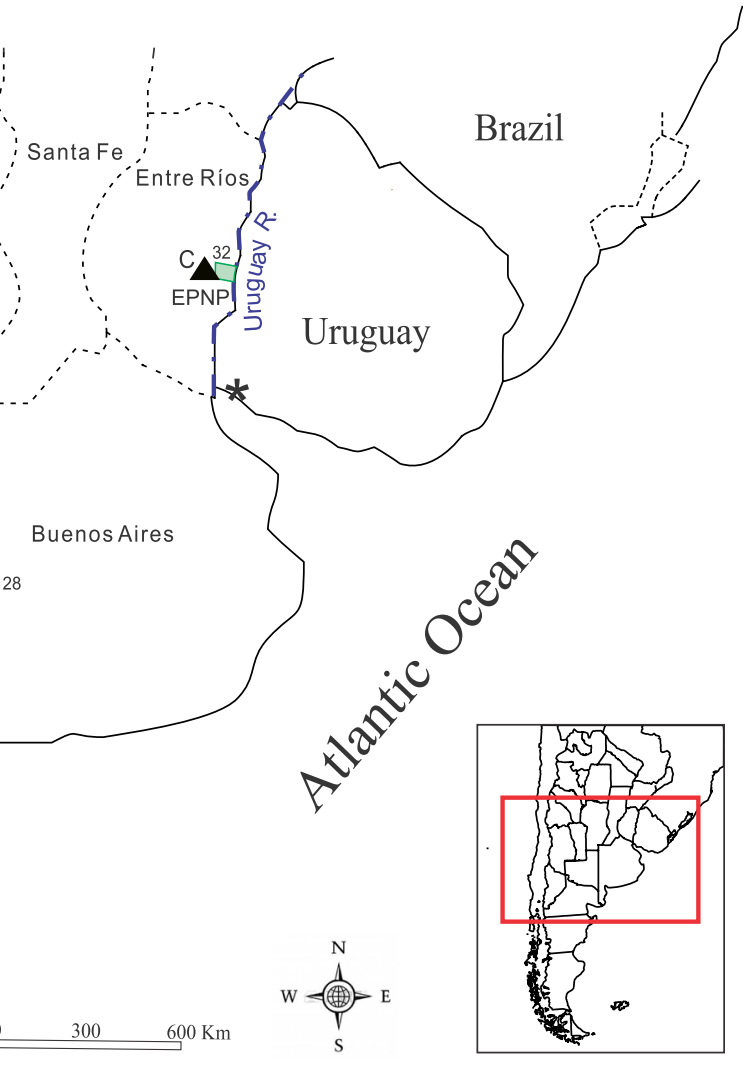

60

55

Collun-Có (Neuquén Province). Green areas represent National Parks $(E P N P=$ El Palmar National Park; PLPR $=$ Parque Luro Provincial Reserve; LNP = Lanín National Park; NHNP = Nahuel Huapi National Park). The asterisk stands for Barra de San Juan (Colonia department, Uruguay). Dashed dotted lines are for Limay, Negro, Colorado, Desaguadero, and Uruguay rivers 
Uruguay (Barra de San Juan Ranch) (Molins 1930; Lombardi et al. 2015). Then, he translocated wild boars from Colonia to Huemul Ranch in Neuquén, although the date of this introduction remains unclear. It is also possible that some boars were taken from PLPR to Colonia in the 1940s (Amieva 1993)

Finally, in the mid-twentieth century, a wild boar population arose in the area currently occupied by El Palmar National Park (EPNP) in Entre Ríos Province (Godoy 1963). Despite the fact that there are not accurate data about their origin, it might be related to PLPR (Zelich pers. comm. 2002).

Starting from the introduction sites, wild boar has expanded its range due to its invasive characteristics and unrecorded human-mediated translocations. Nowadays, the species inhabits a large portion of central Argentina from Chubut and Río Negro in the south, to Córdoba and San Luis in the north; and from the Andes toward the Atlantic Ocean. In Argentina, the wild boar is one of the most important game species, generating significant income for owners of hunting preserves, even though there are no official statistics about this activity. Therefore, individuals are frequently transported from one location to another, both for hunting and for slaughter, to supply the emerging market for wild boar meat in the country. In addition, feral pigs are also present in the country and ancient populations of European origin settled in Río Negro and Buenos Aires (Hudson 1893, 1918). It is a common and uncontrolled practice of local farmers to use feral and wild pigs to improve their domestic stocks (Carpinetti et al. 2014), although natural hybridization is also a possibility. Therefore, it is plausible that some localities may have mixed genetic pools.

In the last decades, several genetic studies allowed to infer origin, expansion process, and divergence between European and Asian wild boars (Giuffra et al. 2000; Kijas and Andersson 2001; Kim et al. 2002; Alves et al. 2003; Larson et al. 2005, 2007; Scandura et al. 2008; Ramírez et al. 2009; Kusza et al. 2014). Studies based on the sequence analysis of mitochondrial genes Cytochrome b (CytB) and Control Region (CR) proved that European and Asian wild boars have diverging lineages and confirmed the existence of three phylogenetic groups: haplogroup E1 (widely distributed in Europe and present in the North of Africa and Near East), E2 (restricted to the Italian peninsula and Sardinia), and haplogroup A (of Asian origin). Nowadays, the presence of the Asian haplogroup in Europe had been attributed to the introgression of Asian sows in Europe to ameliorate domestic pig breeds during the 18th and 19th centuries (Giuffra et al. 2000; Kijas and Andersson 2001; Larson et al. 2005; Ramírez et al. 2009). These genetic markers (CytB and CR) have been vastly used in phylogenetic and phylogeographic analyses in European and Asian wild boar populations (Alexandri et al. 2012; Yu et al. 2013; Kusza et al. 2014; Vilaça et al. 2014), and because of this, their sequences have been used as reference to compare the introduced South American wild boar with the native populations (Grossi et al. 2006; García et al. 2011; Aravena et al. 2015).

The main objective of this work was to use mitochondrial $\mathrm{CR}$ and $\mathrm{CytB}$ sequences to characterize, for the first time, the phylogenetic relationships among wild boars from Argentina, Europe, Asia, the Near East and the neighboring population of Uruguay, as well as domestic pigs, in order to support the historical data about the origin and dispersal of the wild boar in Argentina.

Specific objectives of this work were (1) to corroborate the origin of the Argentinian wild boar populations through phylogenetic analysis, (2) to explore the haplotype distribution among sampling sites, and (3) to evaluate the genetic diversity of Argentinian wild boar and compare it with the existing one in the European populations.

\section{Materials and methods}

In this study, 88 wild boars were sampled within the distribution area of this species in Argentina (Fig. 1). All samples were legally hunted and obtained from licensed hunters and collaborators. Animals were not shot only for the purpose of this study and ethic statement was not required. Hunting was made in accordance with national regulations.

Samples were taken from epithelial and muscular tissue and kept in $96 \%$ ethyl alcohol at $-20{ }^{\circ} \mathrm{C}$. Genomic DNA was extracted following the phenol-chloroform protocol (Sambrook and Russel 2001). A 734 bp fragment of CR between sites 15,390 and 16,124 was amplified by PCR using forward Ss.L-Dloop: 5'CGCCATCAGCACCCAAAGCT3'; and reverse PrR: 5'ACCATTGACTGAATAGCACCT3' primers (Montiel-Sosa et al. 2000; Alves et al. 2003). On the other hand, the complete sequence of the CytB gene (1140 bp) was amplified using two sets of primers: one to obtain a 634 bp fragment between sites 14,109 and 14,743: forward 5'CACGACCAATGACATGAAAAATC3', reverse 5' GCTGCGAGGGCGGTAAT3'; and another set to obtain a 660 bp fragment between sites 14,695 and 15,355: forward 5'TCTTCGCCTTCCACTTTATCCTG3', reverse 5' TGGCCCTCCTTTTCTGGTTTA3' (Alves et al. 2003). Additionally, an internal pair of primers was designed by the authors as some sequences showed a 10-15 bp gap between the two fragments. Forward: 5'ATTCATCCACGTAG GCCGAG3' and reverse: 5'TCAGAATAGGCATTGACTTA GTGGT3', which generated a fragment of 645 bp between the sites 14,484 and 15,129 .

PCR reaction was set to a final volume of $20 \mu \mathrm{L}$ containing 25-100 ng of template DNA, $1.5 \mathrm{mM} \mathrm{Cl}_{2} \mathrm{Mg}, 0.2 \mu \mathrm{M}$ of each primer, $0.2 \mathrm{mM}$ of each dNTP (INBIO), $1 \mathrm{X}$ reaction buffer (INBIO), and $0.5 \mathrm{U}$ of Taq T-Plus DNA polymerase (INBIO). Thermocycling conditions were set at $94{ }^{\circ} \mathrm{C}$ for $2 \mathrm{~min}$ 
followed by 30 cycles at $94{ }^{\circ} \mathrm{C}$ for $45 \mathrm{~s}, 56^{\circ} \mathrm{C}$ for $\mathrm{CytB}$ and $62{ }^{\circ} \mathrm{C}$ for $\mathrm{CR}$ for $45 \mathrm{~s}$, and $74{ }^{\circ} \mathrm{C}$ for 1 min with a final extension of $74{ }^{\circ} \mathrm{C}$ for $10 \mathrm{~min}$ (Alves et al. 2003). Amplification products were purified using $10 \mathrm{U}$ of Exonuclease I (Thermo Scientific) and $1 \mathrm{U}$ of FastAp thermosensible alkaline phosphatase (Thermo Scientific), incubating at $37{ }^{\circ} \mathrm{C}$ for $15 \mathrm{~min}$ and then at $85{ }^{\circ} \mathrm{C}$ for another $15 \mathrm{~min}$ to stop the reaction. These purified PCR products were sequenced by Macrogen Co. Ltd. (South Korea), and haplotype sequences were deposited in the GenBank nucleic acid sequence repository (http://www.ncbi.nlm.nih.gov/genbank) under accession number MH319776-MH319786. Sequences were visually inspected in BioEdit v.7.0.5 (Hall 1999), and multiple sequence alignments were constructed using the ClustalW algorithm (Thompson et al. 1994). Analysis included sequences retrieved from GenBank database, pertaining to European, Near Eastern, Asian, and Uruguayan wild boars (the last one only available for CytB) and also to domestic pig breeds. Sulawesi warty pig (Sus celebensis) sequences were added as outgroup for both genes. For comparison reasons with the GenBank sequences, multiple alignments were reduced in length from 1140 to $570 \mathrm{bp}$ for CytB (132 sequences) and from 734 to 409 bp for CR (559 sequences). This first part of the analysis was carried out with MEGA7 (Kumar et al. 2016). A list of all the sequences used for both genes is detailed in Online Resource 1.

Haplotype and nucleotide diversities (Nei 1987) and number of polymorphic sites were calculated with DnaSP 5.10.1 (Librado and Rozas 2009).

Phylogenetic relations among haplotypes were calculated using Neighbor-Joining (NJ) and Bayesian reconstruction methods. For the NJ phylogeny, the degree of confidence assigned to the nodes was assessed by boot-strapping with 1000 replicates (Felsenstein 1985), and the tree was developed based on the Maximum Composite Likelihood method in MEGA 7 (Kumar et al. 2016). For Bayesian analysis, the model that best fitted the data was calculated based on corrected Bayesian information criteria using JModelTest v2.1.4 software (Darriba et al. 2012). Data was converted to BEAST XML format with BEAUti v.1.7.5 (Drummond et al. 2012). Then, for the tree reconstruction, the following settings were used: a relaxed lognormal clock as molecular clock rate variation model and a 30,000,000 generations Monte Carlo Markov Chain length, sampling every 5000. All calculations were performed in BEAST (Drummond et al. 2012). The first $25 \%$ of the sampling trees and estimated parameters were discarded as burn-in with TreeAnnotator v1.7.5 (Drummond et al. 2012).

Evolutionary relationships among haplotypes were inferred for the CR dataset using the statistical parsimony algorithm, and an haplotype network was built using the Median-Joining algorithm (Bandelt et al. 1999) implemented in PopArt software (Leigh and Bryant 2015).

\section{Results}

A total of seven haplotypes (CR_H1 to CR_H7) were found in the Argentinian samples with $\bar{C}$, five of them shared with GenBank sequences, and two that were never been described before (CR_H4 and CR_H7). For the local set $(n=81)$, we identified 16 polymorphic sites with no singletons (parsimony informative sites) (Table 1) and values of haplotype diversity $\mathrm{Hd}=0.827 \pm 0.017$ and nucleotide diversity $\pi=0.007 \pm$ 0.001 , respectively. On the other hand, four Argentinian haplotypes were detected with $\mathrm{CytB}$ (CB_H1 to CB_H4); three of them shared with GenBank sequences and one that was found in this study (CB_H1). For the 87 local CytB sequences, we identified 13 polymorphic sites with no singletons (Table 1). Haplotype analysis revealed values of haplotype diversity $\mathrm{Hd}=0.596 \pm 0.046$ and nucleotide diversity $\pi=0.005 \pm$ 0.001 , respectively. Number of sequences differ for both genes since $\mathrm{CR}$ amplification failed in six samples from $\mathrm{La}$ Pampa, Río Negro, Buenos Aires, and San Luis. Geographic distribution and frequency of haplotypes can be found in Fig. 2a for CR and Fig. 3a for CytB.

Since Bayesian and NJ phylogenetic trees presented similar topology for both CR and CytB datasets, only the Bayesian trees are shown (Figs. $2 b$ and $3 b$ ). For that approach, the selected models of evolution were $\mathrm{HKY}+\mathrm{I}+\mathrm{G}$ for $\mathrm{CR}$ and HKY + I for CytB (Hasegawa et al. 1985).

The CR tree revealed the presence of well-supported European clades E1 (widely distributed) and E2 (restricted to Italy), the Near Eastern clade (NE) and the Asian clade (A). However, Argentinian haplotypes grouped within the E1 and A clades exclusively (Fig. 2b). Within the E1 clade in particular, the tree topology suggested the existence of a well-supported subgroup that resembles the A-side haplogroup reported in previous studies (Larson et al. 2005, 2007; Scandura et al. 2011; Alexandri et al. 2012). This haplogroup contained three Argentinian haplotypes (CR_H1, CR_H2, and CR_H3) and is reportedly predominant over the region comprised by Italy, France, Germany, and Austria (Larson et al. 2005; Scandura et al. 2011). The remaining haplotypes of the E1 clade roughly matched the previously described C-side haplogroup, which has been reported for the Iberian Peninsula and Central Europe, reaching $90 \%$ of the European wild boars (Larson et al. 2005, 2007; Scandura et al. 2011). Argentinian haplotypes CR_H4, CR_H5, and CR_H7 belonged to this last haplogroup. The A clade included Argentinian haplotype CR_H6. For a detailed composition of the haplotypes see Online Resource 1.

E1 and A clades were also detected in the CytB phylogeny, constructed to identify any relationships between the Argentinian and Uruguayan populations (Fig. 3b). Within E1 clade, three haplotypes belonged to Argentinian sequences (CB H1, CB H2, and CB H3). On the other hand, the A clade was very well supported (posterior probability value $=1$ ) and 


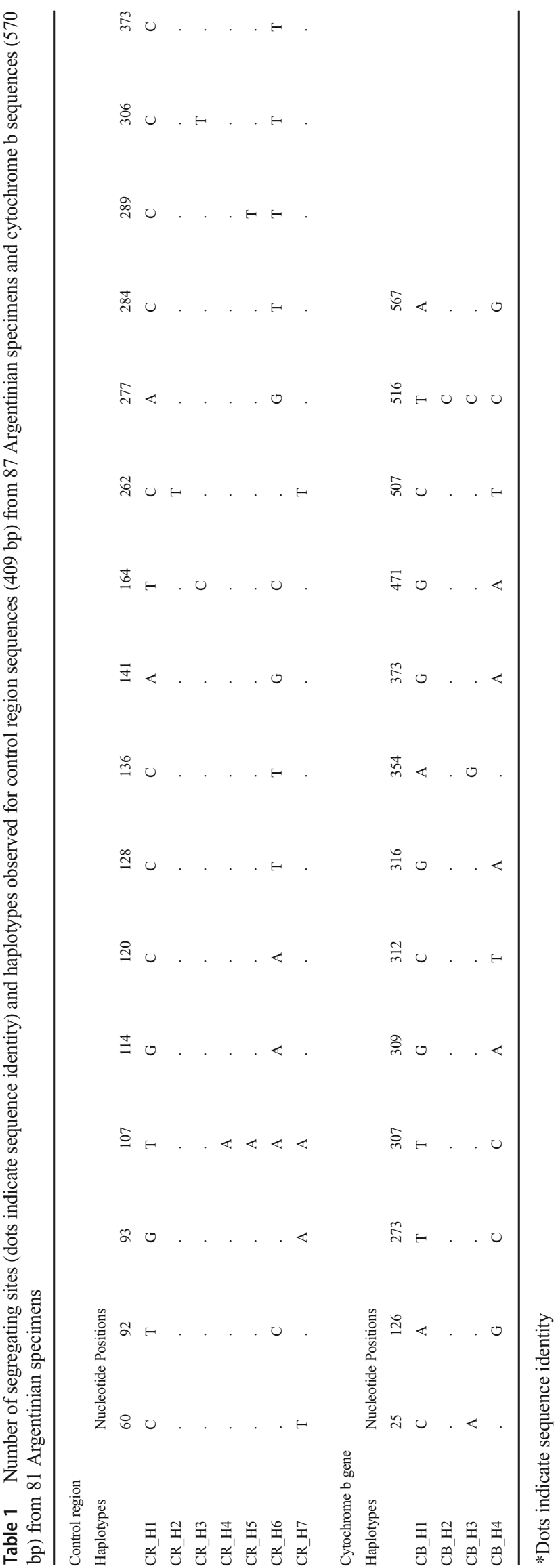

included $\mathrm{CB}$ H4 4 , the only haplotype that grouped sequences from Argentina (in particular from EPNP). Haplotype CB H11 which was previously assigned to the E2 clade (Giuffra et al. 2000) finally collapsed in E1 due to length reduction of the sequences from 1140 to $570 \mathrm{bp}$.

For CR, the median-joining network supported the phylogenetic tree topology showing the relationships among Argentinian haplotypes with the previously defined haplogroups E1-A, E1-C, E2, NE, and A (Larson et al. $2005,2007)$. The network is geographically consistent, with the European and Asian haplotypes clearly differentiated. Within the European subgroup E1-A, a star-like shape was observed, with haplotype CR_H1 located in the central position (Fig. 4).

\section{Discussion}

The present study, the first estimation of the genetic variability of wild boar populations in Argentina, provides preliminary information to elucidate the origin of local populations in this country. Historical records indicate that the wild boar in Argentina has European origins (in particular from France and Spain) and was introduced into the country at the beginning of the twentieth century (Morales 1917; Godoy 1963; Navas 1987; Amieva 1993; Biedma 2003; Novillo and Ojeda 2008).

Phylogenetic analyses partially supported the historical information. The CR phylogeny was consistent with populations in La Pampa and Neuquén descending from wild boars from France and Spain, since their sequences belonged to the E1-A and E1-C haplogroups, respectively. On the other hand, this was not observed in the EPNP population, as all sequences belonged to Asian lineages.

The CR haplotype distribution showed two haplotypes limited to Neuquén (CR_H5 and CR_H7) which accord with the historical introduction of wild boars from the E1-C haplogroup into this province. Haplotype CR_H6, restricted to EPNP, indicates the existence of the Asian lineage in Argentina. The remaining CR haplotypes overlapped in central Argentina toward northern and southern La Pampa, and this could be ascribable to the free movement of animals and unregistered human-mediated translocations among sampling sites. The center of that region was mainly represented by haplotypes from the E1-A haplogroup, which accords with the historical introduction into La Pampa.

In the Neuquén and EPNP populations, no sequences were part of the E1-A haplogroup. This finding does not accord with the occurrence of translocations from La Pampa to these provinces. It is also possible that the E1-A lineage disappeared from these localities in the past. Moreover, the absence of sequences belonging to the NE clade in Argentina does not 


\section{a}

30

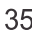

30

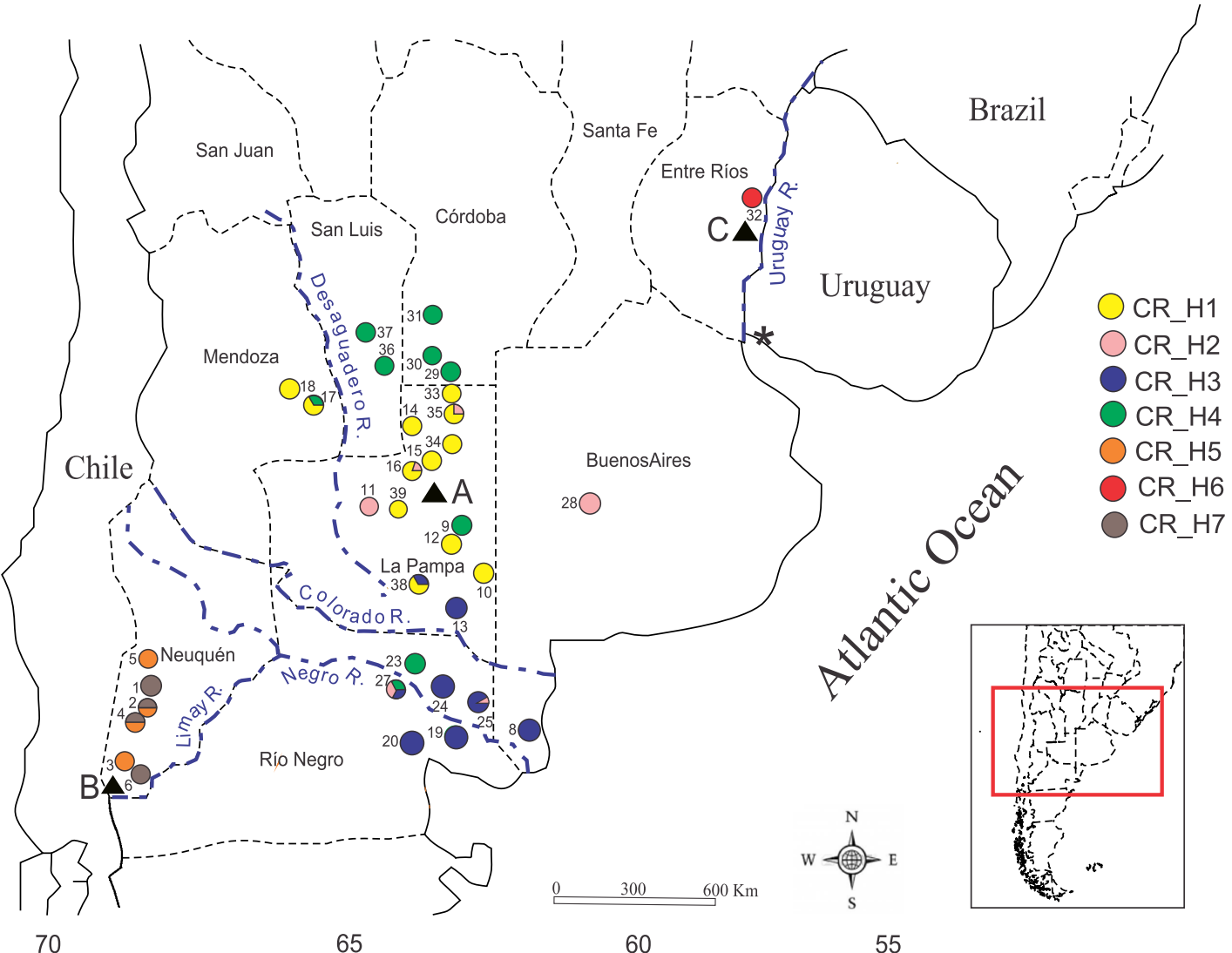

Fig. 2 Control Region haplotypes observed in 81 Argentinian wild boars. (A) Map showing the frequency of the seven CR haplotypes in 35 sampling sites (numbers correspond to the sampling sites detailed in Online Resource 2). (B) Bayesian phylogenetic tree constructed from 74 Control Region haplotypes based on 409 bp sequences from Argentinian wild boars $(n=81)$ and sequences from GenBank $(n=478)$ from previous

studies. Haplotype numbers are indicated from CR_H1 to CR_H74. Haplotypes present in Argentina are highlighted in red and private haplotypes are indicated with arrowheads. Significant posterior probability values $(>0.50)$ are shown on the relevant nodes. Significant bootstrap values of 1000 replicates $(>50 \%)$ from the neighbor-joining tree are shown in brackets

support the hypothesis that wild boars from the Caucasus were introduced into Neuquén.

The Asian origin of wild populations could be explained as crossbreeding between wild boars and domestic pigs (Scandura et al. 2011). Accordingly, the population of EPNP could be a mixture of hybrids that had descended from a hybridization event with local pigs or derive from unrecorded translocations. In either way, there is no evidence of the origin of these animals, and a genetic comparison with the local domestic pigs would support or exclude a hybridization event. The CytB phylogeny also showed that there is a connection between populations from EPNP and Uruguay, as sequences from these two locations shared the same haplotype within the A clade. In Uruguay, the Asian origin of local haplotypes has been attributed to a deliberate introduction of hybrids from southern Brazil; in particular from Rio Grande do Sul State, where wild boar was introduced for crossbreeding with domestic pigs (Grossi et al. 2006; García et al. 2011; Guadagnin et al. 2014). The gallery forests along the Uruguay River toward EPNP could act as natural corridor for dispersal and migration, so in order to clarify the possible relationships among wild boar populations in the three countries, the sampling area should be widened to include Uruguay and Brazil.

As stated in the introduction, wild boars from Colonia (Uruguay) were translocated to Huemul Ranch (Neuquén Province) in the 1920s, and later on, wild boars from PLPR were taken to Colonia (Molins 1930; Daciuk 1978; Amieva 1993; Lombardi et al. 2015). Regarding the relationships among these three populations, in the CytB phylogeny, two haplotypes from the E1 clade comprised all the sequences from La Pampa and the mountain-range part of Neuquén (near Huemul Ranch), together with Uruguayan sequences that represented the historical introduction into Colonia (García et al. 2011). This correspondence could confirm the connection among these three populations, although it was a partial result given that only a short fragment of the gene was analyzed. In summary, it is clear from the results that Argentinian and Uruguayan populations are closely related and must be studied extensively to completely understand their relationships. 
b

CR_H41
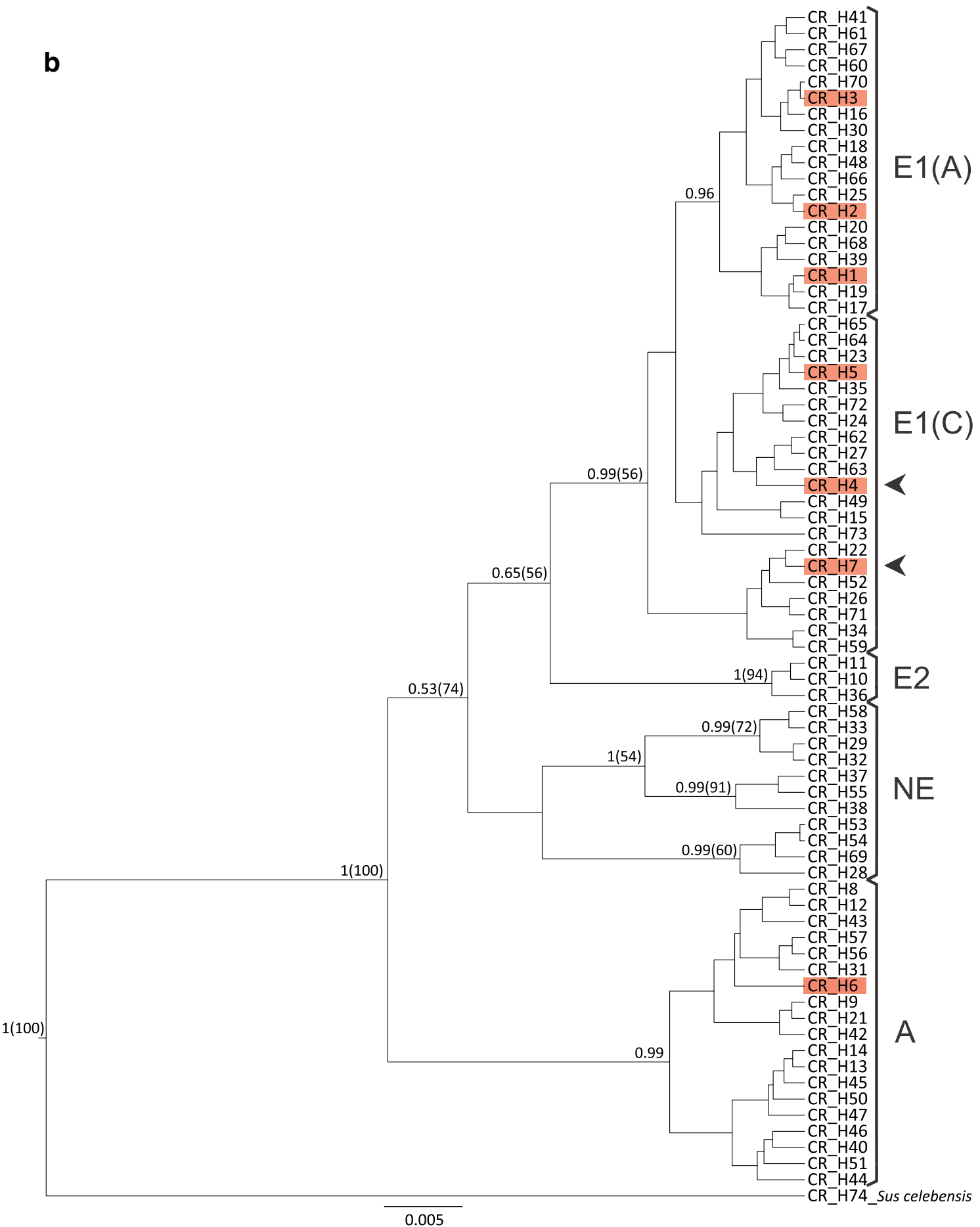

Fig. 2 (continued)

Genetic diversity estimates for the Argentinian populations were lower than those reported for Europe and Uruguay. For the Argentinian CR dataset, the value of haplotype diversity ( $\mathrm{Hd}=0.827 \pm 0.017)$ was lower than Europe $(\mathrm{Hd}=0.902$; Scandura et al. 2008) and the Iberian Peninsula $(\mathrm{Hd}=0.910$; Van Asch et al. 2012); meanwhile, the value of nucleotidic diversity $(\pi=0.007 \pm 0.001)$ was similar to Europe without Italy ( $\pi=0.005$; Scandura et al. 2008) and lower than
European populations altogether $(\pi=0.011$; Scandura 2008). For $\mathrm{CytB}$, both values ( $\mathrm{Hd}=0.596 \pm 0.046$ and $\pi=$ $0.005 \pm 0.001)$ were lower than those obtained for the Uruguayan populations ( $\mathrm{Hd}=0.970$ and $\pi=0.014$; García et al. 2011). The low genetic variation compared to Europe suggests a genetic signature of founder effect in the Argentinian populations, which makes sense since the introduction was recent and composed of only a few animals. On the other 
a

30

35

40

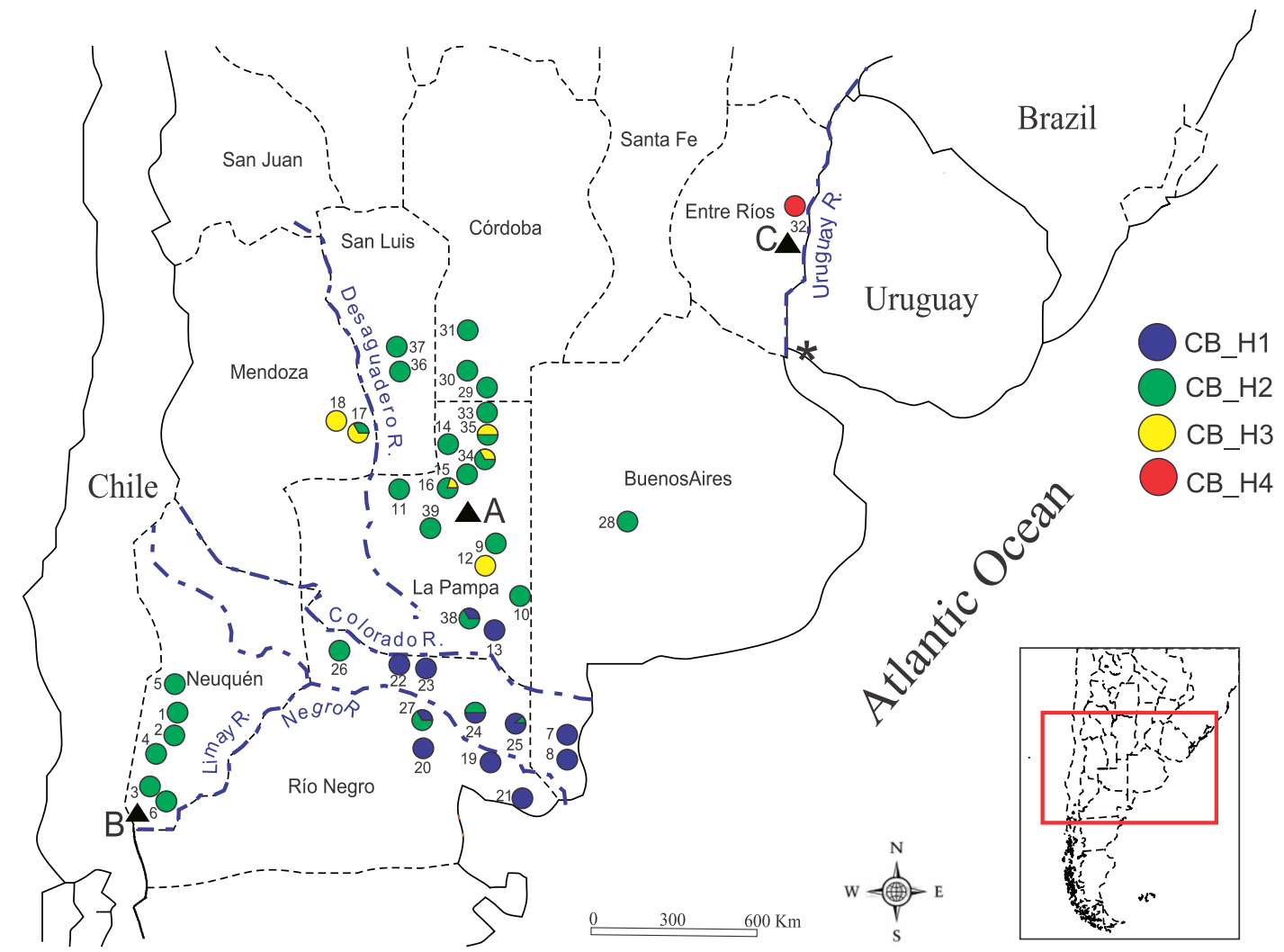

70

65

60

55

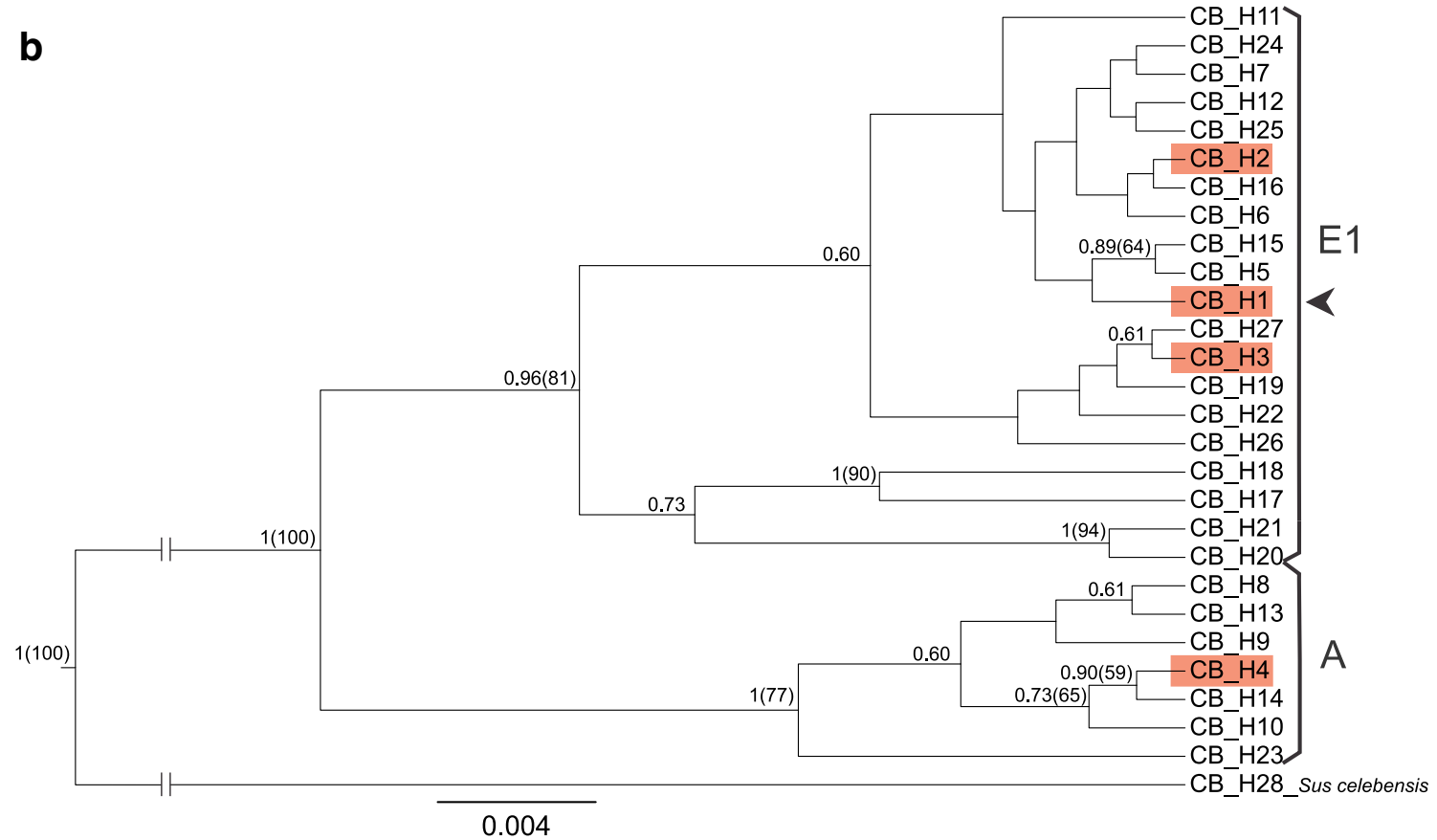

Fig. 3 Cytochrome b haplotypes observed in 87 Argentinian wild boars. (A) Map showing the frequency of the four CytB haplotypes in 39 sampling sites (numbers correspond to the sampling sites detailed in Online Resource 2). (B) Bayesian phylogenetic tree constructed from 28 cytochrome b haplotypes based on 570 bp sequences from Argentinian wild boars $(n=87)$ and sequences from GenBank $(n=45)$ from previous studies. Haplotype numbers are indicated from $\mathrm{CB} \mathrm{H} 1$ to $\mathrm{CB} \mathrm{H} 28$. Haplotypes present in Argentina are highlighted in red and private haplotypes are indicated with arrowheads. Significant posterior probability values $(>0.50)$ are shown on the relevant nodes. Significant bootstrap values of 1000 replicates $(>50 \%)$ for the neighbor-joining tree are shown in brackets 


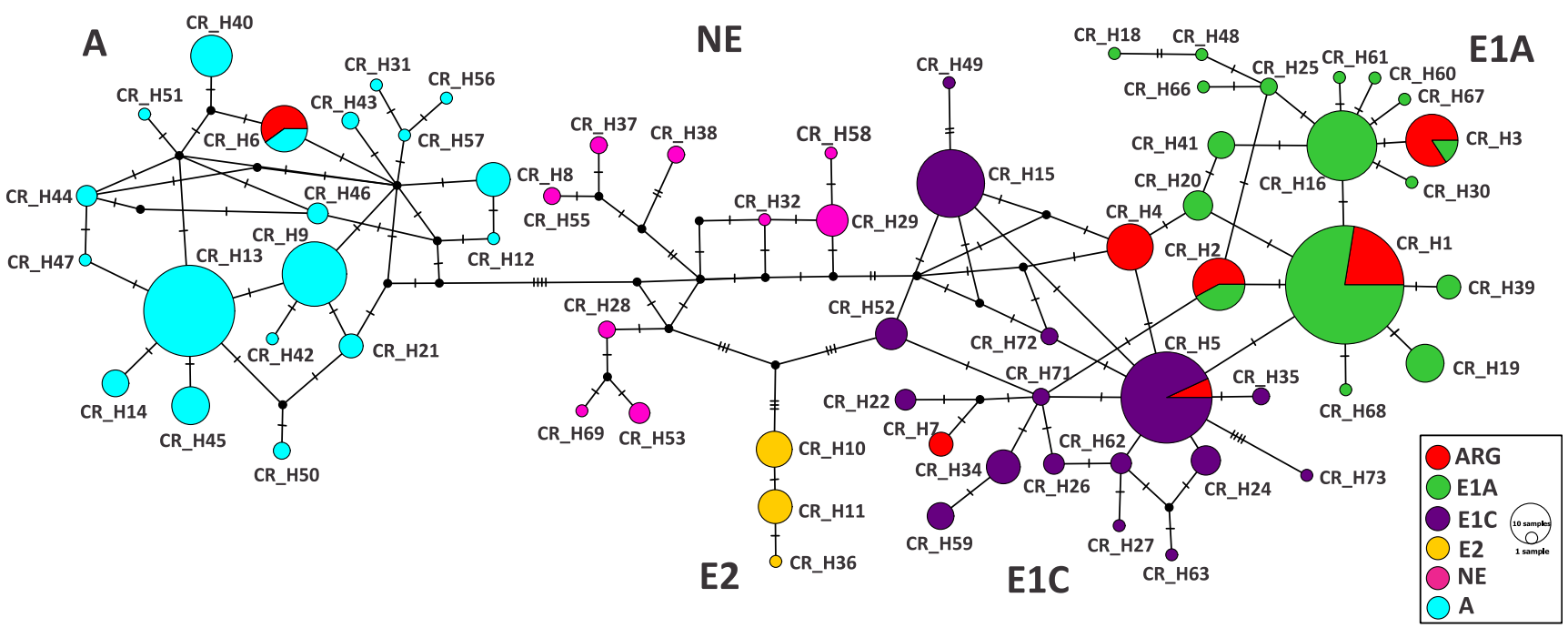

Fig. 4 Median-joining network of mitochondrial CR haplotypes (409 bp) for 74 haplotypes obtained from 559 CR sequences (81 from Argentinian wild boars and 478 from GenBank). Circle size is proportional to haplotype frequencies, colors represent haplogroups and Argentinian

hand, the high values of haplotype diversity and low values of nucleotide diversity observed in Uruguay, had been attributed to the invasive potential of hybrids between wild and domestic pigs (García et al. 2011). A possible explanation for the lower genetic diversity in Argentina compared to Uruguay could be that less hybridization is occurring, making the country a "reservoir" of the original genetic variability. This is supported by the median-joining network results, given that ancestral haplotypes with high frequency in Europe (e.g., haplotypes CR H1 and, to a lesser extent, CR _H5) are the most common in Argentina.

Taken together, the results confirmed the European origin of the majority of the wild boar populations of Argentina, and a different origin for the EPNP population. The use of other molecular markers (e.g., microsatellites) would allow further clarification of the dynamics of Argentinian populations, which would help to develop management plans for this species in the country.

Acknowledgements We thank El Palmar National Park rangers, Guillermo Lier, Eduardo Jones, and Pablo Giorgis. We also express our gratitude to Fabian Tittarelli, Lautaro Córdoba, Lucía Curti, Gabriel Castresana, Pablo Rojas, Marina Winter, and Hernán Amendola for their help in collecting wild boar samples and to Alejandra Canalis for the English revisions. Universidad Nacional del Noroeste de la provincia de Buenos Aires (UNNOBA), Comisión de Investigaciones Científicas de la provincia de Buenos Aires (CICPBA), and Consejo Nacional de Investigaciones Científicas y Técnicas (CONICET) provided financial support for the present research.

\section{Compliance with ethical standards}

Conflict of interest The authors declare that they have no conflict of interest. haplotypes (ARG) are identified in red. Numbers indicate haplotype codes. Major clades (E2, NE, and A) and subgroups of the E1 clade (E1-A and E1-C) are indicated. Transverse bars on the lines indicate the number of mutations between haplotypes

\section{References}

Alexandri P, Triantafyllidis A, Papakostas S, Chatzinikos E, Platis P, Papageorgiou N, Larson G, Abatzopoulos TH, Triantaphyllidis C (2012) The Balkans and the colonization of Europe: the post-glacial range expansion of the wild boar, Sus scrofa. J Biogeogr 39(4):713-723

Alves E, Ovilo C, Rodriguez MC, Silio L (2003) Mitochondrial DNA sequence variation and phylogenetic relationships among Iberian pigs and other domestic and wild pig populations. Anim Genet 34(5):319-324

Amieva EO (1993) El Parque Luro; su origen, su historia, su presente. Fondo Editorial Pampeano, Santa Rosa

Aravena P, Skewes O, Gouin N (2015) Mitochondrial DNA diversity of feral pigs from Karukinka Natural Park, Tierra del Fuego Island, Chile. Genet Mol Res 14(2):4245-4257

Bandelt HJ, Foster P, Rohl A (1999) Median-joining networks for inferring intraspecific phylogenies. Mol Biol Evol 16(1):37-48

Biedma JM (2003) Crónica histórica del Lago Nahuel Huapi. Caleuche, Buenos Aires

Carpinetti BN, Castresana G, Rojas P, Grant J, Marcos A, Monterubbianesi M, Borrás P (2014) Vigilancia epidemiológica en poblaciones de cerdos silvestres (Sus scrofa). Implicancias para la salud pública, la producción animal y la conservación de la biodiversidad. SNS 5:67-76

Crosby AW (1986) Ecological imperialism: the biological expansion of Europe, 900-1900. Cambridge University Press, New York

Daciuk J (1978) IV Estado actual de las especies de mamíferos introducidos en la Subregión Araucana (Rep. Argentina) y grado de coacción ejercido en algunos ecosistemas sur cordilleranos. An Parq Nac 14:105-130

Darriba D, Taboada GL, Doallo R, Posada D (2012) jModelTest 2: more models, new heuristics and parallel computing. Nat Methods 9(8): 772

Drummond AJ, Suchard MA, Xie D, Rambaut A (2012) Bayesian phylogenetics with BEAUti and the BEAST 1.7. Mol Biol Evol 29(8): 1969-1973

Felsenstein J (1985) Confidence limits on phylogenies: an approach using the bootstrap. Evolution 39:783-791 
García G, Vergara J, Lombardi R (2011) Genetic characterization and phylogeography of the wild boar Sus scrofa introduced into Uruguay. Genet Mol Biol 34(2):329-337

Giuffra E, Kijas JMH, Amarger V, Carlborg Ö, Jeon JT, Andersson L (2000) The origin of the domestic pig: independent domestication and subsequent introgression. Genetics 154(4):1785-1791

Godoy JC (1963) Fauna Silvestre. Evaluación de los recursos naturales de Argentina. Tomo VIII. Fauna Silvestre Vol I. Consejo Federal de Inversiones, Buenos Aires

Grossi SF, Lui JF, García JE, Meirelles FV (2006) Genetic diversity in wild (Sus scrofa scrofa) and domestic (Sus scrofa domestica) pigs and their hybrids based on polymorphism of a fragment of the Dloop region in the mitochondrial DNA. Genet Mol Res 5(4):564 568

Guadagnin DL, Carvalho Perello LF, Gomes de Moura R (2014) Distribuiçâo atual do javali (Sus scrofa) no Rio Grande do Sul, seus impactos na produçâo rural e nos ambientes naturais. Dissertation. Federaçâo Gaúcha de Caça e Tiro

Hall TA (1999) BioEdit: a user-friendly biological sequence alignment editor and analysis program for windows 95/98/NT. Nucl acids Symp Ser 41:95-98

Hasegawa M, Kishino H, Yano T (1985) Dating of human-ape splitting by a molecular clock of mitochondrial DNA. J Mol Evol 22:160 174

Hudson WH (1893) Días de ocio en la Patagonia. Continente, Buenos Aires

Hudson WH (1918) Allá lejos y hace tiempo. Peuser, Buenos Aires

Kijas JMH, Andersson L (2001) A phylogenetic study of the origin of the domestic pig estimated from the near-complete mtDNA genome. J Mol Evol 52(3):302-308

Kim KI, Lee JH, Li K, Zhang YP, Lee SS, Gongora J, Moran C (2002) Phylogenetic relationships of Asian and European pig breeds determined by mitochondrial DNA D-loop sequence polymorphism. Anim Genet 33(1):19-25

Kumar S, Stecher G, Tamura K (2016) MEGA7: molecular evolutionary genetics analysis version 7.0 for bigger datasets. Mol Biol Evol 33(7):1870-1874

Kusza S, Podgórski T, Scandura M, Borowik T, Jávor A, Sidorovich VE, Bunevich AN, Kolesnikov M, Jędrzejewska B (2014) Contemporary genetic structure, Phylogeography and past demographic processes of wild boar Sus scrofa population in central and Eastern Europe. PLoS One 9(3):e91401. https://doi.org/10. 1371/journal.pone.0091401

Larson G, Dobney K, Albarella U, Fang M, Matisoo-Smith E, Robins J, Lowden S, Finlayson H, Brand T, Willerslev E, Rowley-Conwy P, Andersson L, Cooper A (2005) Worldwide phylogeography of wild boar reveals multiple centers of pig domestication. Science 307(5715):1618-1621

Larson G, Albarella U, Dobney K, Rowley-Conwy P, Schibler J, Tresset A, Vigne J-D, Edwards CJ, Schlumbaum A, Dinu A, Bălăcssescu A, Dolman G, Tagliacozzo A, Manaseryan N, Miracle P, Van Wijngaarden-Bakker L, Masseti M, Bradley DG, Cooper A (2007) Ancient DNA, pig domestication, and the spread of the Neolithic into Europe. PNAS 104(39):15276-15281

Leigh JW, Bryant D (2015) Popart: full-feature software for haplotype network construction. Methods Ecol Evol 6(9):1110-1116

Librado P, Rozas J (2009) DnaSP v5: a software for comprehensive analysis of DNA polymorphism data. Bioinformatics 25(11): $1451-1452$
Lombardi R, Geymonat G, Berrini R (2015) El jabalí en el Uruguay. Problema, desafío y oportunidad. Forestal Atlántico Sur, Montevideo

Molins JW (1930) Industrias rurales: Uruguay, 1830-1930: Imprenta Latina, Montevideo

Montiel-Sosa JF, Ruiz-Pesini E, Montoya J, Roncalés P, Lopéz-Pérez MJ, Pérez-Martos A (2000) Direct and highly species-specific detection of pork meat and fat in meat products by PCR amplification of mitochondrial DNA. J Agric Food Chem 48:2829-2832

Morales EB (1917) Lagos, selvas y cascadas. Descripciones geográficas. Peuser, Buenos Aires

Navas JR (1987) Los vertebrados exóticos introducidos en Argentina. Rev. Mus. Argentino Cienc. Nat., n.s Tomo XIV (2): 7-38

Nei M (1987) Molecular evolutionary genetics. Columbia University Press, New York 512pp

Novillo A, Ojeda RA (2008) The exotic mammals of Argentina. Biol Invasions 10(8):1333-1344

Oliver WLR, Brisbin IL (1993) Introduced and feral pigs: problems, policy and priorities. In: Oliver WLR (ed) Status survey and conservation action plan: pigs, peccaries and hippos. IUCN, gland, pp 179-191

Oliver W, Leus K (2008) Sus scrofa. The IUCN Red List of Threatened Species 2008: e.T41775A10559847. https://doi.org/10.2305/IUCN. UK.2008.RLTS.T41775A10559847.en

Ramírez O, Ojeda A, Tomas A, Gallardo D, Huang LS, Folch JM, Clop A, Sanchez A, Badaoui B, Hanotte O, Galoman-Omitogun O, Makuza SM, Soto H, Cadillo J, Kelly L, Cho IC, Yeghoyan S, Perez-Enciso M, Amills M (2009) Integrating Y-chromosome, mitochondrial, and autosomal data to analyze the origin of pig breeds. Mol Biol Evol 26(9):2061-2072

Read AF, Harvey PH (1989) Life history differences among the eutherian radiations. J Zool 219(2):329-353

Sambrook J, Russel DW (2001) Rapid isolation of yeast DNA. In: Sambrook J, Russel DW (eds) Molecular cloning, a laboratory manual. Cold Spring Harbor Laboratory Press, New York, pp 631-632

Scandura M, Iacolina L, Crestanello B, Pecchioli E, Di Benedetto MF, Russo V, Davoli R, Apollonio M, Bertorelle G (2008) Ancient vs. recent processes as factors shaping the genetic variation of the European wild boar: are the effects of the last glaciation still detectable? Mol Ecol 17(7):1745-1762

Scandura M, Iacolina L, Apollonio M (2011) Genetic diversity in the European wild boar Sus scrofa: phylogeography, population structure and wild x domestic hybridization. Mammal Rev 41(2):125137

Thompson JD, Higgins DG, Gibson TJ (1994) CLUSTAL W: improving the sensitivity of progressive multiple sequence alignment through sequence weighting, position-specific gap penalties and weight matrix choice. Nucleic Acids Res 22(22):4673-4680

Van Asch B, Pereira F, Santos LS, Carneiro J, Santos N, Amorim A (2012) Mitochondrial lineages reveal intense gene flow between Iberian wild boars and south Iberian pig breeds. Anim Genet 43(1):35-41

Vilaça ST, Biosa D, Zachos F, Iacolina L, Kirschning J, Alves PC, Paule L, Gortazar C, Mamuris Z, Jedrzejewska B, Borowik T, Sidorovich VE, Kusak J, Costa S, Schley L, Hartl GB, Apollonio M, Bertorelle G, Scandura M (2014) Mitochondrial phylogeography of the European wild boar: the effect of climate on genetic diversity and spatial lineage sorting across Europe. J Biogeogr 41(5):987-998

Yu G, Xiang H, Wang J, Zhao X (2013) The phylogenetic status of typical Chinese native pigs: analyzed by Asian and European pig mitochondrial genome sequences. J Anim Sci biotechnol 4(1):9 